\title{
Multidisciplinary Guidelines for Occupational Risk Prevention
}

\author{
Luciano José Minette ${ }^{1 *}$, José Dionísio De Paula ${ }^{1}$ and Josimáteus Geraldo Ataíde Rocha da Silva ${ }^{2}$ \\ ${ }^{1}$ Department in Forestry Sciences, Federal University of Viçosa, Brazil \\ ${ }^{2}$ Faculty Presidente Antônio Carlos, Brazil
}

Received: June 05, 2018; Published: June 21, 2018

*Corresponding author: Luciano José Minette, Department in Forestry Sciences, Federal University of Viçosa. Av. P. H. Rolfs, s/nº, Brazil

\begin{abstract}
Objective: Evaluate the relationship between the psychosocial variables with professional aspects and sociodemographic characteristics of workers in the furniture manufacturing and the corresponding multidisciplinary intervention. Methods: The study sample consisted of 146 workers in the sector of production of two industries of furniture, divided into two groups: Group 1 (study) and group 2 (control). Group 1 was formed by 80 workers and by Group 2 of 66 workers. The instrument used to evaluate Common Mental Disorders was the Self Reporting Questionnaire (SRQ-20) and the Job Content Questionnaire (JCQ) was used to assess the psychosocial factors in the work environment. Results: The results showed sign can't difference at the "authority of decision" ( $p=0,05)$, "control over the job" $(p=0,03)$ and "physical effort" $(p=0,02)$ dimensions when comparing the groups of workers. There were not sign can't differences in the other variables. There were no significant differences in other variables. Conclusion: Comparing both Groups revealed relation between "decision authority", "decision latitude" and "physical exertion" variables, with the multidisciplinary intervention.
\end{abstract}

Keywords: Occupational Health; Multidisciplinary Intervention; Workers; Mental Health

\section{Introduction}

The worker's health is a public health whose object of study and intervention the relationship between work and health [1,2]. Thus, it is understood by workers' health the body of knowledge from different disciplines, such as Public Health, Medicine, Sociology, Epidemiology, Engineering, Psychology, among many others, which together with the scientific knowledge on occupational health, establishes a new way of understanding the relationship between health and work [3].

\section{Methods}

Analytical study with cross temporality. The study sample consisted of 146 workers from two furniture industries manufacturing sector. Said sample was divided into two groups, called Group 1 (study), Group 2 (control). The study group consisted of 80 workers, and the control group, 66 workers. The scenarios of the research were two furniture factories in the city of Ubá, Minas Gerais, Brazil, which has $407452 \mathrm{~km} 2$ of land area and population of 101519 inhabitants1. Considered one of the major cities of Minas Gerais Forest Zone, Ubá stands out for its large commercial and industrial center. The company classified as study group, workers were invited to participated in multidisciplinary guidelines for pro fessionals from different areas. Multidisciplinary interventions occurred over a month in the place specified by the company, during work hours, lasting one hour, occurring in the early hours of work, always preceding the start of the working day. Multidisciplinary interventions for the furniture industry workers were in the form of lectures, professionals were composed of: Social Worker (Social conditions and family planning), Nurse (Sanitary Conditions in the workplace), Physiotherapist (Ergonomics at work), Nutritionist (health and nutrition in the workplace) and psychologist (Stress and mental health).

The instruments used in the study to evaluate the common mental disorders It was the Self-Reporting Questionnaire - (SRQ). As for psychosocial factors in the workplace we used the Job Content Questionnaire (JCQ) It addresses the evaluation of existing psychosocial aspects exclusively on the desktop. To measure the psychosocial factors at work we used the recommended version of Job Content Questionnaire (JCQ) Robert A. Karasek [4]. Validated and translated in Brazil [5,6]. Inclusion criteria were male workers, working in the company's production sector, which agreed to participate in the research by presenting the "Informed Consent and Informed - IC" which was present on the day of the survey, with a 
minimum of six months with the company, minimum of one year of work in the mobile industry, who were not using antidepressants with being ages 20 and 60 years.

The participants were only workers who had Common Mental Disorder indicators (CMD), it was used for screening the SRQ-20, with a cutoff value of 5/6, which was considered indicative of CMD from 6 positive responses [7]. Whereas, it is a male population. Exclusion criteria were female workers and they were doing some psychological treatment in the investigation period. This study complied with all ethical standards for research involving human beings, requirements of Resolution No. 196/96 of the National Health Council. Data were organized and inserted spreadsheet program IBM, SPSS Version 20 (Statistical Package for the Social Sciences) in the form of electronic database, followed by entering the data into two separate spreadsheets for Group 1 and Group 2.

The variables analyzed were classified as predictors: psychological demands; control at work (ability to use and decision-making authority); physical demand; social support (social support by the supervisor and social support by colleagues); job insecurity; type of work (theoretical model); exposure to stress at work (theoretical model); presence of common mental disorders. modifying var- iable effect: multidisciplinary and outcome variable intervention: mental health. Therefore, non-parametric tests were performed Mann-Whitney U test and Kruskal-Wallis test. Mann-Whitney U test for independent groups to determine the size of the effect on the JCQ variables [8] The level of significance for all study $p \leq 0.05$.

\section{Results}

Over the working hours in the company, the study group showed mean 5,81anos (SD \pm 6.15 ), the control group mean 4.80 years ( $\mathrm{SD} \pm 4.31)$. For the working time in the furniture industry, the study group showed a mean 10.92 years ( $\mathrm{SD} \pm 9.07$ ) and control group mean 6.94 years (SD \pm 6.14 ), shown in Table 1 . In the analyzes of the tests used in Table 2, the test Mann-Whitney U showed statistically significant $(r=0.16 ; p=0.05)$ with the variable deciding authority for the study group ( $\mathrm{Md}=32.00, \mathrm{n}=80$ ) and control group ( $M d=28.00, n=66)$ showing positive and weak association. About job control, the relationship between the study groups $(\mathrm{Md}=$ $64.00, \mathrm{n}=80)$ and control group ( $M d=61.00 ; n=66)$ showed a positive association and weak $(r=0.17 ; \mathrm{p}=0.03)$. The variable physical effort made ( $\mathrm{r}=0.18 ; \mathrm{p}=0.02)$ Study group $(\mathrm{Md}=7.50, \mathrm{n}=80)$ and control group $(\mathrm{Md}=8.00 ; \mathrm{n}=66)$. For the other variables were not found statistically significant associations relevant and positive for the groups.

Table 1: labor activity time workers investigated in mobile industries.

\begin{tabular}{|c|c|c|c|c|c|c|c|c|c|c|}
\hline \multirow[t]{2}{*}{$\begin{array}{c}\text { Time } \\
\text { (years) }\end{array}$} & \multicolumn{5}{|c|}{ Study $(\mathrm{N}=\mathbf{8 0})$} & \multicolumn{5}{|c|}{ Control $(\mathrm{N}=66)$} \\
\hline & $\mathbf{n}$ & Average & DP & median & Mini-Max & $\mathbf{n}$ & Average & DP & median & Mini-Max \\
\hline Company & 80 & 5.81 & 6.15 & 4.00 & $\begin{array}{l}0.58 \text { to } \\
32.00\end{array}$ & 66 & 4.80 & 4.31 & 3.00 & $\begin{array}{c}0.58 \text { to } \\
17.00\end{array}$ \\
\hline $\begin{array}{l}\text { Furniture } \\
\text { industry }\end{array}$ & 80 & 10.92 & 9.07 & 7.00 & $\begin{array}{l}1.00 \text { to } \\
34.00\end{array}$ & 66 & 6.94 & 6.14 & 5.00 & $\begin{array}{l}0.58 \text { to } \\
22.00\end{array}$ \\
\hline
\end{tabular}

Table 2: Analysis by comparing the variables of the JCQ dimensions for groups of workers assessed

\begin{tabular}{|c|c|c|c|c|c|c|c|c|c|}
\hline \multirow[t]{2}{*}{ JCQ } & \multicolumn{4}{|c|}{ Study $(n=80)$} & \multicolumn{4}{|c|}{ Control $(n=66)$} & \multirow[b]{2}{*}{$\mathbf{P}^{*}$} \\
\hline & Average & DP & median & $\operatorname{mini}$ Max & Average & DP & median & $\operatorname{mini}$ Max & \\
\hline Use Skills & 33.00 & 5.47 & 33.00 & $16.00-48.00$ & 31.97 & 4.82 & 32,00 & $22.00-44.00$ & 0.11 \\
\hline Decision authority & 31.65 & 6.47 & 32,00 & $12.00-44.00$ & 29.64 & 6.03 & 28.00 & $16.00-44.00$ & 0.05 * \\
\hline Control at work & 64.65 & 10.43 & 64.00 & $30.00-92.00$ & 61.61 & 9.30 & 61.00 & $38.00-88.00$ & $0.03 *$ \\
\hline Psychological demand & 32.18 & 4.33 & 32.00 & $22.00-44.00$ & 30.56 & 5.06 & 31.00 & $12.00-42.00$ & 0.08 \\
\hline Physical effort & 7.45 & 1.85 & 7.50 & $3.00-12.00$ & 8.18 & 2.13 & 8.00 & $3.00-12.00$ & $0.02 *$ \\
\hline Isometric physical load & 4.85 & 1.37 & 5.00 & $2.00-8.00$ & 5.03 & 1.46 & 5.00 & $2.00-8.00$ & 0.54 \\
\hline physical demand & 12.30 & 2.76 & 12.00 & $5.00-18.00$ & 13.21 & 3.23 & 13.00 & $5.00-20.00$ & 0.08 \\
\hline Job insecurity & 7.35 & 0.97 & 7.00 & $6.00-10.00$ & 7.21 & 1.05 & 7.00 & $5.00-9.00$ & 0.46 \\
\hline Social support coworker & 11.78 & 2.02 & 12.00 & $4.00-16.00$ & 11.79 & 2.10 & 12.00 & $5.00-16.00$ & 0.88 \\
\hline $\begin{array}{l}\text { Supervisor of social } \\
\text { support }\end{array}$ & 11.04 & 2.18 & 11.00 & $4.00-15.00$ & 10.82 & 2.07 & 11.00 & $7.00-16.00$ & 0.26 \\
\hline
\end{tabular}




\section{Conclusion}

Regarding the predictive variables, the results indicate that multidisciplinary interventions showed significant difference between the groups for the variables "Deciding authority", "Control at work" and "Physical effort".

\section{References}

1. (2001) Ministry of Health, Pan American Health Organization. Related Diseases to work, Manual procedures for health services, Brasilia DF, Brazil.

2. Dejours Ca (2007) work crazy: study of psychopathology of work $\left(5^{\text {th }}\right.$ edn.), São Paulo: Cortez Oboré, Brazil.

3. Albrecht KG (1979) Stress and the manager. Prentice - Hall, New Jersey, USA.

4. Karasek RA (1985) Job Content Questionnaire and user's guide, revision 1.1. Lowell, MA University of Massachusetts, Department of work environment Massachusetts, USA.

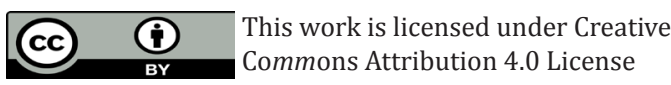

Submission Link: https://biomedres.us/submit-manuscript.php
5. Araujo Tm (1999) Labor and psychiatric disorders among workers in nursing women. 1999 210f. Thesis (Doctorate in Public Health) - Health Collective Institute, Federal University of Bahia, Salvador, Brazil.

6. Araujo TM, Karasek RA (2008) Validity and reliability of the job content informal and informal questionnaire jobs in Brazil. Scandinavian Journal of Work Environment and Health 6: 52-59.

7. Souza SF (2009) Work and Mental Health maintenance workers of an electricity transmission generation system. Dissertation (Masters in Health, Environment and Labor) - School of Medicine. Federal da Bahia Unibersidade, Bahia, Brazil.

8. Pallant JA (2007) Step by Step Guide to Data Analysis using SPSS for Windows third edition Open University Press. McGraw-Hill, New York, USA.

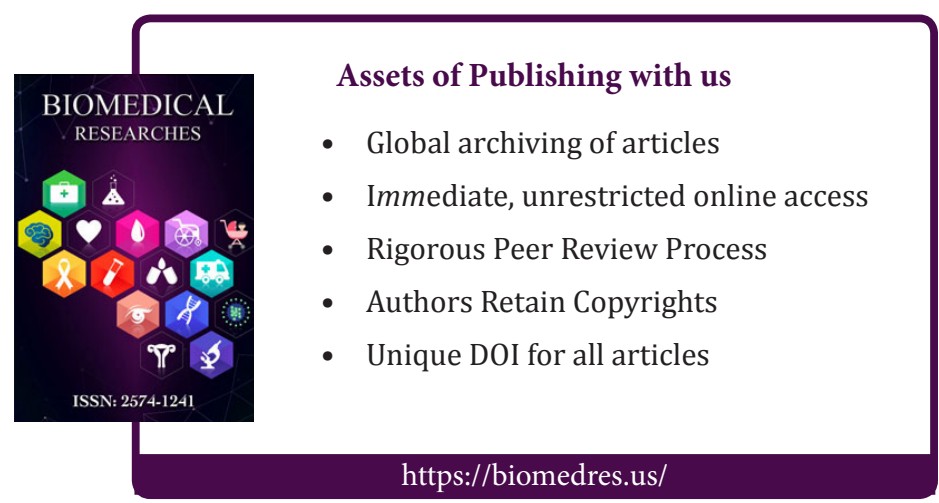

